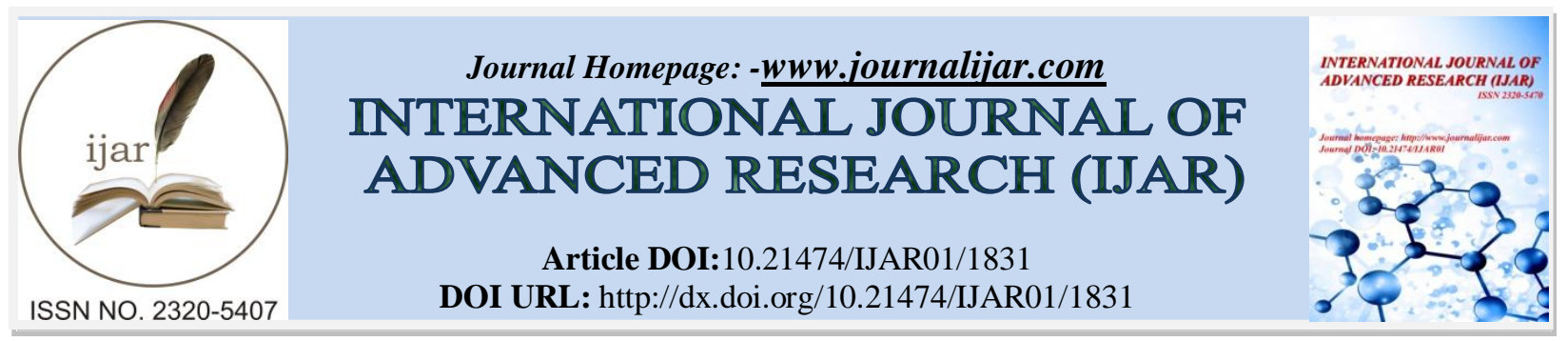

RESEARCH ARTICLE

\title{
EFFECT OF SINGLE NEOCLEOTIDE POLYMORPHISM OF RECK GENE PROMOTER ON HEPATOCELLULAR CARCINOMA: IN CORRELATION WITH CLINICAL AND LABORATORY PARAMETERS.
}

\author{
Nahla I. Elattar ${ }^{1}$, Samar M. Sharaf ${ }^{1}$, Afify F. Afify ${ }^{2}$ and Reem M. Allam ${ }^{1, *}$. \\ 1. Clinical Pathology Faculty of Medicine, Zagazig University, Egypt. \\ 2. Internal Medicine Departments, Faculty of Medicine, Zagazig University, Egypt.
}

\section{Manuscript Info}

\section{Manuscript History}

Received: 12 August 2016

Final Accepted: 22 September 2016

Published: October 2016

Key words:-

Hepatocellular carcinoma, RECK, SNP,Real time PCR.

\section{Abstract}

Background:-Hepatocellular carcinoma (HCC) is the second most common cancer in men and the $6^{\text {th }}$ most common cancer in women in Egypt. It constitutes $70.48 \%$ of all liver tumors among Egyptians. Thereversion-inducing-cysteine-rich protein with Kazal motifs (RECK) gene encodes a membrane-anchored glycoprotein that can negatively regulate matrix metalloproteinases (MMPs) and inhibit tumor invasion, angiogenesis, and metastasis.

Objective:-This study investigates the potential effect of RECK gene promoter single nucleotide polymorphisms (SNPs) with HCC susceptibility on clinical and laboratory characteristics in Egyptian patients.

Methods:-A number of $50 \mathrm{HCC}$ cancer patients and 50 cancer-free controls were analyzed for RECK promoter rs10814325 genotyping using real-time PCR. Clinical staging and assay of AFP and liver function tests were performed for all participants.

Results:-Having RECK promoter rs10814325 mutant genotypes TC/CC showed a $\mathbf{2 . 7 0 4}$-fold [95\% confidence interval (CI), 1.197 6.113] higher risk of developing HCC compared to TT wild type carriers. A significant association between clinical stage III/IV and RECK promoter rs10814325 mutant genotypes. However no significant association between laboratory parameters and RECK promoter genotypes.

Conclusions:-RECK gene promoterpolymorphisms might be a risk factor increasing HCC susceptibility and clinical stage progression.

Copy Right, IJAR, 2016,. All rights reserved.

\section{Introduction:-}

Hepatocellular carcinoma (HCC) is rated as the fifth most frequently diagnosed cancer in adult men worldwide, and is considered the second leading cause of cancer-related death(Jemal et al., 2011). While in adult women, it is the seventh most commonly diagnosed cancer and the sixth leading cause of cancer-related death (El-Serag and Kanwal, 2014). A variety of important risk factors for the development of HCC have been identified. These include HBV infection, chronic HCV infection, hereditary hemochromatosis and cirrhosis of almost any cause (Davila et al., 2004). Ultrasoundis the most common imaging tool used to screen for HCC thanks to its features such as simplicity, low cost and minimal invasiveness (Aghoram et al., 2012; Song et al., 2014). Serum AFP is the most extensively 
applied biomarker for HCC surveillance (EASL-EORTC, 2012). However, its low sensitivity (20\% to 65\%) and specificity (50\% to 94\%) in discovering early HCC has resulted in the latest American guidelines abandoning AFP but using ultrasonography alone as the single surveillance tool (Bruix and Sherman, 2011).

The human reversion-inducing-cysteine-rich protein with Kazal motifs (RECK) gene is located on chromosome region 9p13-p12 (Takahashi et al., 1998). RECK gene is normally expressed in all cells of the body and has an important role in the balance between destructive and constructive features of the extracellular matrix (ECM) (Alexius-Lindgren et al., 2014). RECK protein is a membrane-anchored glycoprotein that contains three serine protease inhibitor-like (SPI) domains. These SPIs are believed to inhibit the protease activity of at least 3 MMPs, (MMP-2 and MMP-9) and MT1-MMP post-transcriptionally (Clark et al., 2007). MMP-2 and MMP-9 break down ECM both under normal conditions and during pathological conditions. Down-regulation of RECK gene correlates with tumor invasiveness and poor survival. This can be explained by role of RECK as inhibitor of MMPs (Oh et al., 2001). RECK down-regulation, promoter hyper-methylation and decreased RECK expression have been confirmed in many human cancers (Masui et al., 2003; Takenaka et al., 2004; Takeuchi et al., 2004; Y Zhang et al., 2012). The genomic structure for the RECK gene has been identified and 4 of total 13 SNPs were recognized in coding region (Eisenberg et al., 2002). RECK promoter SNP has been evaluated in several human cancers and evidenced to have role in detecting susceptibility and progression (Lei et al., 2007; Chung et al., 2011; Chen et al., 2014). Thus, the aim of this work is to analyze the association between RECK gene promoter SNP (rs10814325) and HCC susceptibility and clinical and laboratory parameters in Egypt.

\section{Materials and methods:-}

\section{Study design and sample selection:}

This is a case control study carried out in Clinical Pathology Department and Internal Medicine DepartmentAdvanced Centre for liver diseases, Zagazig University Hospitals. The study included 100 subjects classified into;

* 50 newly diagnosed patients with hepatocellular carcinoma (diagnosed by abdominal sonography, computed tomography and/or magnetic resonance imaging).

* 50 matched healthy controls.

The two groups were matched in age and sex. Patients underwent any treatment protocol resection, radiofrequency, trans-arterial chemoembolization or palliative medical treatment, or having other malignancy had been excluded from the study. The study protocol was approved by the institutional ethics committee and written informed consent was obtained from all participants.

HCC patients were staged clinically at the time of diagnosis according to the TNM staging system $\left(7^{\text {th }}\right.$ edition) of the American Joint Committee on Cancer (AJCC) (2010). Liver cirrhosis was diagnosed with abdominal ultrasonography or biochemical evidence of liver parenchymal damage with endoscopic esophageal or gastric varices. All members of this study were subjected to the following, liver function tests on Cobas 6000 analyser series c501, prothrombin time and INR on Sysmex CA-1500, AFP, HBsAg and anti-HCV Ab by electrochemileumencence technique on Cobas e411 analyser and RECK promoter rs10814325 genotyping by realtime PCR technique. A Child-pugh score was calculated for patients.

\section{Sample collection:-}

$3 \mathrm{ml}$ of peripheral venous blood was taken in plain vacutainer tube for routine laboratory investigations while $2 \mathrm{ml}$ was collected on di-potassium EDTA $(1 \mathrm{mg} / \mathrm{ml})$ and immediately stored at $-80^{\circ} \mathrm{C}$ for DNA extraction and analysis of gene polymorphism.

\section{Genomic DNA extraction from whole blood:-}

DNA was isolated using the QIAamp DNA Mini Kit (QIAGEN) according to the instructions of manufacturer. DNA was dissolved in AE buffer and then quantified by a measurement of OD260 on Nanodrop 2000 spectrophotometer (ThermoScientific). Final preparation was stored at $-20^{\circ} \mathrm{C}$ and used as templates for polymerase chain reaction (PCR).

\section{Real-time PCR:-}

The allelic discrimination of the RECK rs10814325 gene polymorphisms was assessed with the ABI StepOne ${ }^{\mathrm{TM}}$ Real-Time PCR System (Applied Biosystems) and analyzed using Step one software v2.3 (Applied Biosystems), using the TaqMan assay (assay IDs: C_27084758_10). The final volume for each reaction was $20 \mu \mathrm{L}$, containing 10 $\mu \mathrm{L}$ TaqMan Genotyping Master Mix, 1.0 $\mu \mathrm{L}$ TaqMan probes mix, $20 \mathrm{ng}$ genomic DNA and reaching the final 
volume with RNAse-free water. The real-time PCR reaction included an initial denaturation step at $95^{\circ} \mathrm{C}$ for $10 \mathrm{~min}$, followed by 40 cycles, each consisting of $95^{\circ} \mathrm{C}$ for $15 \mathrm{sec}$ and $60^{\circ} \mathrm{C}$ for $1 \mathrm{~min}$.

\section{Interpretation of results:-}

Allelic discrimination plot on Step one software discriminates type of RECK gene rs10814325 SNP TT, TC or CC according to the detected dye VIC or FAM with normalization against passive reference dye ROX. TT is the wild genotype while Homozygous CC and Heterozygous TC are the high risk (mutant) genotypes.

\section{Statistical analysis:-}

The sample size was calculated with $80 \%$ statistical power and $95 \%$ confidence interval (CI). All data were collected, tabulated and statistically analyzed using SPSS 16.0 for windows (SPSS Inc., Chicago, IL, USA). Chisquare test was used to examine the relation between qualitative variables. For quantitative data, comparison between two groups was done using Independent t-test, Mann-Whitney test or Kruskal-wallis or H test (for nonparametric data) and ANOVA or F test (for comparing more than two groups) as appropriate. Odds ratio (OR) with its $95 \%$ confidence interval $(\mathrm{CI})$ were used for risk estimation. A p-value $<0.05$ was considered significant.

\section{Results:-}

The cases and controls appeared to be well matched on age and sex where the distributional differences of age [HCC: $61.58 \pm 7.42$; control: $60.98 \pm 6.84$ ) and sex (HCC: 40 males (80\%) and 10 females (20\%); control: 33 males $(66 \%)$ and 17 females $(34 \%)$ ] were insignificant $(\mathrm{p}=0.68$ and 0.115$)$, respectively. Between HCC patients $44 \%(22$ of 50) were smokers, while those of controls were 32\% (16 of 50). The distributional difference of smoking between healthy controls and patients with HCC was insignificant $(\mathrm{p}=0.22)($ Table 1$)$.

Table 1:-Demographic characteristics of study subjects.

\begin{tabular}{|l|c|c|c|c|}
\hline Parameter & $\begin{array}{c}\text { HCC cases } \\
(\text { No. }=50)\end{array}$ & $\begin{array}{c}\text { Controls } \\
(\text { No. }=50)\end{array}$ & Test of significance & $p$ value \\
\hline Age (years) & $\begin{array}{c}\text { (1.58 } \\
(44-8.42\end{array}$ & $\begin{array}{c}60.98 \pm 6.84 \\
(47-70)\end{array}$ & $\mathrm{t}=0.42$ & 0.68 \\
\hline Sex Male/Female & $\begin{array}{c}40 / 10 \\
(80 / 20 \%)\end{array}$ & $(66 / 34 \%)$ & $\chi 2=2.49$ & 0.115 \\
\hline Smoking & $22(44 \%)$ & $16(32 \%)$ & $\chi 2=1.35$ & 0.22 \\
Non-smoking & $28(56 \%)$ & $34(68 \%)$ & & \\
\hline
\end{tabular}

No.: Number of subjects

\# Data are presented as No. $(\%)$ or mean \pm SD (range)

Table 2 shows the genotype distributions and the association between HCC and gene polymorphisms of RECK. The genotype with the highest distribution frequency for RECK gene rs10814325 in HCC patients was homozygous CC, while in healthy controls was wild TT genotype. People with RECK gene rs10814325 TC, CC, TC+CC showed a 3.5-fold (95\% CI: 0.576 - 21.283), 2.625-fold (95\%CI: 1.139 - 6.06), or 2.704-fold (95\%CI: 1.197 - 6.113) higher risk of HCC compared to wild type individuals.

Table 2:-Odds ratio of RECK gene rs10814325 genotype distribution among HCC cases and controls

\begin{tabular}{|l|c|c|c|c|}
\hline Genotype & $\begin{array}{c}\text { HCC cases } \\
\text { (No. }=\mathbf{5 0})\end{array}$ & $\begin{array}{c}\text { Controls } \\
\text { (No. = 50) }\end{array}$ & OR (95\% C.I) & p value \\
\hline TT & $16(32 \%)$ & $28(56 \%)$ & 1.00 & \\
\hline TC & $4(8 \%)$ & $2(4 \%)$ & $\mathbf{3 . 5}(0.576-21.283)$ & 0.2 \\
\hline CC & $30(60 \%)$ & $20(40 \%)$ & $\mathbf{2 . 6 2 5}(1.139-6.06)$ & $\mathbf{0 . 0 2 2} *$ \\
\hline TC+CC & $34(68 \%)$ & $22(44 \%)$ & $\mathbf{2 . 7 0 4}(1.197-6.113)$ & $\mathbf{0 . 0 1 5} *$ \\
\hline
\end{tabular}

The distribution frequency of risk factors (including $\mathrm{HBsAg}$, anti-HCV Ab, and liver cirrhosis) and clinical characteristics (including TNM clinical staging, primary tumor size, lymph node involvement, distant metastasis and Child-Pugh grade) and RECK genotypes frequencies in HCC patients were estimated to clarify the role of RECK gene polymorphisms in the clinical states of HCC patients. There was no observed significant association between the RECK rs10814325 genotype and risk factors (Table 3) or for clinical states except for clinical stage in which stage III/IV was significantly higher among cases with CC genotype $(\mathrm{p}<0.01)$ (Table 4$)$. 
Table 3:-Relationship between risk factors in HCC patients and genotype.

\begin{tabular}{|c|c|c|c|c|c|}
\hline \multicolumn{2}{|l|}{ Risk factors } & $\begin{array}{c}\text { TT } \\
(\text { No. }=16)\end{array}$ & $\begin{array}{c}\mathrm{TC}+\mathrm{CC} \\
(\mathrm{No} .=34)\end{array}$ & $\chi^{2}$ & p value \\
\hline HBs Ag & $\begin{array}{l}\text { +ve } \\
\text {-ve }\end{array}$ & $\begin{array}{l}7(43.8 \%) \\
9(56.2 \%) \\
\end{array}$ & $\begin{array}{l}13(38.2 \%) \\
21(61.8 \%)\end{array}$ & 0.138 & 0.71 \\
\hline Anti HCV & $\begin{array}{l}+v e \\
\text {-ve }\end{array}$ & $\begin{array}{c}10(62.5 \%) \\
6(37.5 \%)\end{array}$ & $\begin{array}{l}17(50 \%) \\
17(50 \%)\end{array}$ & 0.68 & 0.41 \\
\hline Cirrhosis & $\begin{array}{l}\text { +ve } \\
\text {-ve }\end{array}$ & $\begin{array}{c}12(75 \%) \\
4(25 \%)\end{array}$ & $\begin{array}{l}24(70.6 \%) \\
10(29.4 \%)\end{array}$ & 0.105 & 0.75 \\
\hline
\end{tabular}

Data are presented as No. $(\%)$

Table 4:-Relationship between clinical characteristics of HCC patients and genotype.

\begin{tabular}{|c|c|c|c|c|}
\hline Clinical characteristics & TT $\quad($ No. $=16)$ & $\begin{array}{c}\mathrm{TC}+\mathrm{CC} \\
(\mathrm{No} .=34)\end{array}$ & $\chi^{2}$ & $p$ value \\
\hline $\begin{array}{l}\text { Clinical stage } \\
\text { I / II } \\
\text { III/IV }\end{array}$ & $\begin{array}{c}14(87.5 \%) \\
2(12.5 \%)\end{array}$ & $\begin{array}{l}11(32.4 \%) \\
23(67.6 \%)\end{array}$ & 13.24 & $<0.0003 *$ \\
\hline $\begin{array}{l}\text { Tumor size } \\
\leq \mathrm{T} 2 \\
>\mathrm{T} 2\end{array}$ & $\begin{array}{c}11(68.8 \%) \\
5(31.2 \%)\end{array}$ & $\begin{array}{l}14(41.2 \%) \\
20(58.8 \%)\end{array}$ & 3.31 & 0.07 \\
\hline $\begin{array}{l}\text { Lymph node } \\
\text { No } \\
\text { N1 }\end{array}$ & $\begin{array}{c}15(93.8 \%) \\
1(6.2 \%)\end{array}$ & $\begin{array}{c}31(91.2 \%) \\
3(8.8 \%)\end{array}$ & Fisher exact & 1 \\
\hline $\begin{array}{l}\text { Distant metastasis } \\
\text { M0 } \\
\text { M1 }\end{array}$ & $\begin{array}{c}15(93.8 \%) \\
1(6.2 \%)\end{array}$ & $\begin{array}{c}32(94.1 \%) \\
2(5.9 \%)\end{array}$ & Fisher exact & 1 \\
\hline $\begin{array}{l}\text { Child pugh } \\
\text { A } \\
\text { B/C }\end{array}$ & $\begin{array}{c}11(68.8 \%) \\
5(32.2 \%)\end{array}$ & $\begin{array}{l}17(50 \%) \\
17(50 \%)\end{array}$ & 1.55 & 0.21 \\
\hline
\end{tabular}

* High statistical significant $(\mathrm{p}<0.01)$

There was no observed significant association between the RECK rs10814325 genotype and laboratory parameters assayed, including liver function tests (serum total and direct bilirubin, serum total protein, serum albumin, serum alanine aminotransferase and aspartate aminotransferase) and AFP (Table 5).

Table 5:-Association between laboratory data of HCC cases and high risk RECK gene rs10814325 genotypes.

\begin{tabular}{|c|c|c|c|c|}
\hline Parameters & $\begin{array}{c}\text { TT } \\
(\text { No. }=16)\end{array}$ & $\begin{array}{c}\mathrm{TC}+\mathrm{CC} \\
(\mathrm{No} .=34)\end{array}$ & t test & p value \\
\hline Serum Total bilirubin (mg/dl) & $\begin{array}{c}1.44 \pm 0.74 \\
(0.5-3.4)\end{array}$ & $\begin{array}{c}1.39 \pm 0.75 \\
(0.5-3.5)\end{array}$ & 0.195 & 0.85 \\
\hline Serum Direct bilirubin (mg/dl) & $\begin{array}{c}0.67 \pm 0.54 \\
(0.1-2.2)\end{array}$ & $\begin{array}{c}0.72 \pm 0.56 \\
(0.1-2.3)\end{array}$ & 0.299 & 0.77 \\
\hline Serum Total protein $(\mathrm{gm} / \mathrm{dl})$ & $\begin{array}{c}6.98 \pm 0.65 \\
(6-8)\end{array}$ & $\begin{array}{c}6.81 \pm 0.86 \\
(4.9-8.5)\end{array}$ & 0.73 & 0.47 \\
\hline Serum Albumin (gm/dl) & $\begin{array}{c}3.19 \pm 0.38 \\
(2.5-3.7)\end{array}$ & $\begin{array}{c}3.36 \pm 0.63 \\
(2.5-4.4)\end{array}$ & 1.04 & 0.31 \\
\hline Serum ALT (IU/L) & $\begin{array}{c}89.58 \pm 25.79 \\
(54-131.2)\end{array}$ & $\begin{array}{c}91.71 \pm 21.88 \\
(53.2-133)\end{array}$ & 0.32 & 0.75 \\
\hline Serum AST (IU/L) & $\begin{array}{c}133.8 \pm 42.48 \\
(84-220.4)\end{array}$ & $\begin{array}{c}131.85 \pm 34.67 \\
(73.7-238.3)\end{array}$ & 0.178 & 0.86 \\
\hline Serum AST/ALT ratio & $\begin{array}{c}1.5 \pm 0.2 \\
(1.2-1.92)\end{array}$ & $\begin{array}{c}1.45 \pm 0.2 \\
(1.13-1.83)\end{array}$ & 0.89 & 0.37 \\
\hline Serum AFP (ng/ml) & $\begin{array}{c}228.7 \pm 142.17 \\
(44-1873)\end{array}$ & $\begin{array}{c}542.5 \pm 158.44 \\
(36.2-3458)\end{array}$ & $\begin{array}{c}\text { Mann- } \\
\text { Whitney } \\
1.83\end{array}$ & 0.067 \\
\hline
\end{tabular}

Data are presented as mean \pm SD (range) except for AFP median \pm SEM 


\section{Discussion:-}

This study evaluates the effects of single nucleotide polymorphisms of RECK gene promoter on HCC susceptibility and clinical status association. Rs10814325 SNP was located at promoter sites and was predicted to change transcription factor binding sites by TRANSFAC. A clinical research from Germany shows that breast cancer patients carrying rs10814325 -402 T/C SNP have a greater chance of survival than those carrying T/T wild type (Lei et al., 2007).

In this study, the frequencies of RECK gene rs $10814325 \mathrm{TT}$, TC and CC were $32 \%, 8 \%$ and $60 \%$, respectively. While in Taiwan the frequencies were $28.5 \%, 44.9 \%$ and $26.5 \%$, respectively and in Sweden were $83.7 \%, 15.8 \%$ and 0.5\%, respectively (Lei et al., 2007; Chung et al., 2011). There is an ethnic difference in frequencies of RECK gene rs10814325 among different populations. This, in turn explains the variations in different researches.

This study showed that having CC or TC+CC genotypes increases HCC risk by 2.625 folds (95\% C.I $1.139-6.06$ ) and 2.704 folds (95\% C.I $1.197-6.113$ ) respectively compared to TT wild genotype with statistical significant differences between cases and controls ( $\mathrm{p}<0.05$ ). This emphasize role of RECK promoter rs10814325 genotyping in detecting risk of developing HCC in high risk people. Chung et al.,(2012) reported similar results in Taiwan. They reported that having CC or TC + CC genotype increases HCC risk by 2.184 (95\%CI: 1.211-3.939), and 1.85 folds (95\% CI: 1.027-3.361) respectively.

Furthermore, this study showed that there was significant difference between $\mathrm{HCC}$ and control groups as regard type of allele (p 0.028). Using the T allele as the reference, presence of $\mathrm{C}$ allele increase $\mathrm{HCC}$ risk by 2.447 folds (95\% C.I 1.095 - 5.468).

There was no observed significant association between the RECK rs10814325 genotype and risk factors, clinical or laboratory parameters except for clinical stage of the patient [stage III/IV was significantly higher among cases with CC genotype $(\mathrm{p}<0.01)]$. These results go in hand with (Chung et al., 2012) who reported similar results in Taiwan except for clinical stage which had insignificant association with RECK promoter rs10814325 genotype.

Using PCR-RFLP technique (Badawy et al., 2015) studied role of another RECK gene polymorphism rs16932912 and (Gaber et al., 2015) studied role of two RECK gene polymorphisms rs16932912 and rs11788747 on HCC susceptibility and clinical features. Chung et al., (2012) in Taiwan, studied RECK gene promoter rs10814325 by realtime PCR, besides other 3 RECK gene polymorphisms rs16932912, rs11788747 and rs10972727 by PCR-RFLP technique.

Chung et al., (2012) found that patients with rs16932912, rs11788747, and rs10972727 genes of RECK polymorphism showed no higher risk of HCC compared to wild type individuals. Also (Badawy et al., 2015) reported that RECK rs16932912 mutant genotypes GG/AG frequencies showed no higher risk of HCC compared to wild type individuals ( $\mathrm{p}=0.373$ ). While (Gaber et al., 2015) showed that RECK rs11788747 mutant homozygous genotype GG and all mutant genotypes AG/GG frequencies have higher risk of HCC compared to wild genotype ( $\mathrm{p}=0.006$ and 0.030 respectively) but RECK rs16932912 gene showed no statistical significance.

Chung et al., (2012) who reported that there was no observed significant association between the rs16932912 and rs10972727 gene polymorphisms and clinical states. However, they found among HCC patients, those who had rs11788747 SNPs had a higher risk of distant metastasis ( $\mathrm{p}=0.003$ ) than wild type patients. Gaber et al., (2015) also showed that RECK rs11788747 mutant genotypes AG/GG frequencies showed higher risk of lymph node metastasis compared to wild genotype $(\mathrm{p}=0.034)$.

Chung et al., (2012) studied effect of other RECK gene SNPs on ALT, AST and AFP. They found no significant difference for all results except for ALT levels that were significantly different between the rs11788747 AA and AG/GG genotypes $(\mathrm{p}=0.05)$. Gaber et al., (2015) showed that the levels of ALT, AST, and ALP were significantly higher among the rs11788747 mutant AG/GG genotypes versus wild AA genotype ( $\mathrm{p}=0.011,0.001$ and 0.003 ), respectively. Badawy et al., (2015) showed high significant levels of ALT, AST, AFP and ALB (P=<0.01) among the rs 16932912 mutant AG/AA genotypes versus wild GG genotype. 
Another study performed RECK promoter genotyping in oral cancer in Taiwan and they found that RECK gene polymorphisms were not associated with oral cancer susceptibility but RECK rs10814325 polymorphism have a 2.26-fold risk to have neck lymph node metastasis compared with RECK wild-type carrier (Chung et al., 2011).

Chen et al., (2014) studied RECK gene polymorphisms in NSCLC in Chinese. They found that the CC carriers of rs10814325 TC polymorphisms had significantly higher risk for NSCLC. But for the chemotherapy response status, the genetic polymorphisms of RECK gene did not show positive association with the chemotherapy response status in patients with advanced NSCLC.

RECK was highly expressed in normal biliary cells, whereas intrahepatic cholangiocarcinoma showed low levels of expression. Down regulation of RECK was correlated with tumor metastasis $(\mathrm{p}<0.01)$ and shorter patient survival ( $\mathrm{p}<0.02$ ) (Namwat et al., 2011).

The methylation state of RECK gene affects its expression and so it was evaluated by many researchers. As a tumor suppressor gene, RECK gene hyper-methylation can lead to silencing and so decreased expression followed by highly invasive characters of the tumor. Zhou et al., (2014) investigated the effects of a DNA methyltransferase (DNMT) inhibitor, 5-aza29deoxycytidine (5-aza-dC), on the methylation status and expression of the RECK gene and tumor invasion in salivary adenoid cystic carcinoma (SACC) using methylation specific PCR (MSP), Western blot analysis, and quantitative real-time PCR. They showed that 5-aza-dC inhibited cancer cell invasion through the reversal of RECK gene hyper-methylation, which might be a promising chemotherapy approach in SACC treatment.

Also miRNA proved in many studies to have a role in regulating RECK gene expression and so determining tumor behavior. Leite et al., (2015) studied effect of different miRNAs on behavior of cancer prostate in Brazil. They found that miR-21 overexpression decreased RECK gene expression. This negative control of RECK caused MMP9 overexpression promoting tumor cell invasion. So miR-21 could be considered as an oncomiRNA related to aggressiveness in prostate cancer.

\section{Conclusion:-}

Our result supports the role of peripheral blood RECK promoter rs10814325 genotyping as non-invasive test in determining the susceptibility of at risk individuals to HCC.

Genotypes CC or CC+TC genotype increases HCC risk by $\mathbf{2 . 6 2 5}$ and $\mathbf{2 . 7 0 4}$ folds respectively with statistical significant difference between cases and controls.

Presence of $\mathrm{C}$ allele increase $\mathrm{HCC}$ risk by $\mathbf{2 . 4 4 7}$ folds with statistical significant difference between cases and controls.

Genotypes CC or TC is associated with advanced HCC clinical stage. Stage III/IV was significantly higher among cases with TC or CC genotypes.

\section{Conflict of interest:-}

The authors have no conflict of interest to declare.

\section{References:-}

1. Aghoram R, Cai P, and Dickinson JA (2012)

Alpha-foetoprotein and/or liver ultrasonography for screening of hepatocellular carcinoma in patients with chronic hepatitis B. Cochrane Database Syst Rev9:2799.

2. Alexius-Lindgren M, Andersson E, Lindstedt I, et al (2014)

The RECK gene and biological malignancy--its significance in angiogenesis and inhibition of matrix metalloproteinases. Anticancer Res34:3867-3873.

3. Badawy I, Darwish MK, Samir O, et al (2015)

RECK Gene Polymorphisms in Hepatocellular Carcinoma and Cirrhotic Patients Related to Hepatitis C Virus. Donnish J Biomed Res2:1-6.

4. Bruix J, and Sherman $M$ (2011)

Management of hepatocellular carcinoma: an update. Hepatol Baltim Md53:1020-1022.

5. Chen X, Jiang F, Shi N, et al (2014) 
RECK Gene Polymorphisms Influence NSCLC Susceptibility, but not the Chemotherapy Response Status in Chinese Cohort. Cell Biochem Biophys69:567-571.

6. Chung T-T, Pan M-S, Kuo C-L, et al (2011)

Impact of RECK gene polymorphisms and environmental factors on oral cancer susceptibility and clinicopathologic characteristics in Taiwan. Carcinogenesis32:1063-1068.

7. Chung T-T, Yeh C-B, Li Y-C, et al (2012)

Effect of RECK Gene Polymorphisms on Hepatocellular Carcinoma Susceptibility and Clinicopathologic Features. PLOS ONE7:e33517.

8. Clark JCM, Thomas DM, Choong PFM, et al (2007)

RECK--a newly discovered inhibitor of metastasis with prognostic significance in multiple forms of cancer. Cancer Metastasis Rev26:675-683.

9. Davila JA, Morgan RO, Shaib Y, et al (2004)

Hepatitis C infection and the increasing incidence of hepatocellular carcinoma: a population-based study. Gastroenterology 127:1372-1380.

10. EASL-EORTC (2012)

EASL-EORTC clinical practice guidelines: management of hepatocellular carcinoma. J Hepatol56:908-943.

11. Eisenberg I, Hochner H, Sadeh M, et al (2002)

Establishment of the genomic structure and identification of thirteen single-nucleotide polymorphisms in the human RECK gene. Cytogenet Genome Res97:58-61.

12. El-Serag HB, and Kanwal F (2014)

Epidemiology of hepatocellular carcinoma in the United States: where are we? Where do we go? Hepatol Baltim Md60:1767-1775.

13. Gaber AA, Darwish TE, Farhan HM, et al (2015)

RECK gene polymorphisms in hepatocellular carcinoma: association with susceptibility and clinicopathologic features in Egyptian patients. Int J Adv Res3:880-887.

14. Jemal A, Bray F, Center MM, et al (2011)

Global cancer statistics. CA Cancer J Clin61:69-90.

15. Lei H, Hemminki K, Altieri A, et al (2007)

Promoter polymorphisms in matrix metalloproteinases and their inhibitors: few associations with breast cancer susceptibility and progression. Breast Cancer Res Treat 103:61-69.

16. Leite KRM, Reis ST, Viana N, et al (2015)

Controlling RECK miR21 Promotes Tumor Cell Invasion and Is Related to Biochemical Recurrence in Prostate Cancer. J Cancer6:292-301.

17. Masui T, Doi R, Koshiba T, et al (2003)

RECK expression in pancreatic cancer: Its correlation with lower invasiveness and better prognosis. Clin Cancer Res9:1779-1784.

18. Namwat N, Puetkasichonpasutha J, Loilome W, et al (2011)

Downregulation of reversion-inducing-cysteine-rich protein with Kazal motifs (RECK) is associated with enhanced expression of matrix metalloproteinases and cholangiocarcinoma metastases. J Gastroenterol46:664-675.

19. Oh J, Takahashi R, Kondo S, et al (2001)

The membrane-anchored MMP inhibitor RECK is a key regulator of extracellular matrix integrity and angiogenesis. Cell107:789-800.

20. Song $P$, Tang $W$, and Kokudo $N$ (2014)

Serum biomarkers for early diagnosis of hepatocellular carcinoma. Transl Gastrointest Cancer3:103-105.

21. Takahashi C, Sheng Z, Horan TP, et al (1998)

Regulation of matrix metalloproteinase-9 and inhibition of tumor invasion by the membrane-anchored glycoprotein RECK. Proc Natl Acad Sci U S A95:13221-13226.

22. Takenaka K, Ishikawa S, Kawano Y, et al (2004)

Expression of a novel matrix metalloproteinase regulator, RECK, and its clinical significance in resected non-small cell lung cancer. Eur J Cancer Oxf Engl 199040:1617-1623.

23. Takeuchi T, Hisanaga M, Nagao M, et al (2004)

The membrane-anchored matrix metalloproteinase (MMP) regulator RECK in combination with MMP-9 serves as an informative prognostic indicator for colorectal cancer. Clin Cancer Res Off J Am Assoc Cancer Res 10:5572-5579.

24. Zhang Y, Cheng S, Zhang G, et al (2012)

Low expression of RECK indicates a shorter survival for patients with invasive breast cancer. Cancer Sci103:10841089.

25. Zhou XQ, Huang SY, Zhang DS, et al (2014)

Effects of 5-aza-2'deoxycytidine on RECK gene expression and tumor invasion in salivary adenoid cystic carcinoma. Braz J Med Biol Res48:254-260. 